\title{
Physico-Chemical Characterization of Local Tannery Waste Water Before and After Flocculation Treatment
}

\author{
Abba Paltahe ${ }^{1,2}$, Tsamo Cornelius ${ }^{2}$, Balkissou Sambo ${ }^{3}$, Djaoyang Christian ${ }^{2}$, Téri Téri ${ }^{2}$, Danga Rallet ${ }^{3}$, Abdoul \\ Wahabou $^{2}$ \\ ${ }^{1}$ Mineral Chemistry Laboratory, Faculty of Sciences, University of Yaounde I, Cameroon \\ ${ }^{2}$ Department of Chemistry, HigherTeachers'Training College, University of Maroua, Cameroon \\ ${ }^{3}$ Department of Chemistry, Faculty of Sciences, University of Maroua, Cameroon \\ Correspondence: Abba Paltahe, Department of Chemistry, HigherTeachers'Training College, University of Maroua, \\ Cameroon.
}

Received: June 4, 2019 Accepted: July 1, 2019 Online Published: July 22, 2019

doi:10.5539/ijc.v11n2p77 URL: https://doi.org/10.5539/ijc.v11n2p77

\begin{abstract}
This paper presents the variation in physico-chemical properties of a local Maroua tannery effluent before and after a flocculation treatment. Tanning is a process that consists of the transformation of the animal skin into leather by using different baths which contain many chemical reagents and produces high quantity of liquid and solid waste. The used water of traditional tannery of Maroua is directly thrown in nature without any pre-treatment posing a potential risk to the environment and human health. Physico-chemical parameters such as temperature, $\mathrm{pH}$ and conductivity, Total suspended solids, Total hardness, chlorides, sulfides, nitrates, $\mathrm{COD}, \mathrm{BOD}_{5}$, ammonium ion, dissolve oxygen, turbidity, colour and odour were determined before and after aluminum sulfate powder flocculation treatment for effluents collected from soaking, liming, deliming and vegetable tanning stages of the tannery process. The results obtained showed that most of the physico-chemical parameters are higher than the international standard. The results obtained made it possible to classify these four effluents in order of toxicity as follows: Liming water > vegetable tanning water > deliming water $>$ soaking water. The treatment of these waste waters by flocculation reduces the concentrations of certain pollutant loads such as TSS, turbidity, hardness, COD, BOD 5 , sulfate; but remains less effective on others such as nitrate, chloride and ammonium ion $(8 \%)$. There is also a decrease in $\mathrm{pH}$, an increase in dissolved oxygen and conductivity. The flocculation treatment thus considerably reduced the toxicity of these effluents, especially its organic load.
\end{abstract}

Keywords: used water, traditional tannery of Maroua, analysis, flocculation

\section{Introduction}

Tannery is one of the most important activities in the traditional crafts of Maroua. It involves the transformation of animal skins into leathers that can be used for the manufacture of handbags, shoes, belts, etc. The raw materials used for tannery are derivatives from the meat industry. The tanning process, almost completely a wet process generates about $90 \%$ of the used water as effluent (Chowdhury et al. 2013, 2015). Tannery effluents are very polluted due to the presence of highly colored compounds, sodium chloride and sulphate, various organic and inorganic substances, toxic metallic compounds, different types of tanning materials which are biologically oxidizable, and large quantities of putrefying suspended matter (Imran et al., 2012; Chowdhury et al. 2013). During the process of developing leather from raw hide (grouped into three main stages: river work or soaking and liming, tanning and finishing (Figure 1)), the tanning industry uses several baths containing environmentally harmful chemicals to treat the skins. As a result, it produces enormous amounts of wastewater with serious environmental threats due to high chemical levels including salinity, conductivity, chemical oxygen demand (COD), biological oxygen demand (BOD), inorganic matter, suspended solids (SS), total dissolved solids (TDS), and heavy metals etc (Bishnu et Al, 2016). Generally, water consumption is the highest in the pre-tanning areas, but significant amounts of water are also consumed in the post-tanning processes. The soaking stage, the most polluting stage of the tanning process, contributes around 50-55\% of the total pollution load of the tanning industry. In the liming stage, protein, hair, skin and emulsified fats are removed from the hides, then are released in the effluent and increase its total solids contents (Chowdhury et al. 2015; Amanial, 2016; Muthukkauppan and Parthiban, 2018). The effluents from the tan-yard processes, de-liming and bating contain sulphides, ammonium salts, and calcium salts, and the effluent is slightly alkaline. The pickling and chrome tanning 
effluents contain sulphuric acid, chrome, chlorides, sodium bicarbonate and sulphates. Tannery wastewater is often discharged into the receiving environment (sea, rivers and soils) without prior treatment affecting the receiving water quality in several ways (Shegani, 2014); its biodegradable organic compounds cause a strong reduction in the amount of dissolved oxygen in surface waters while its macro-nutrients such as phosphorus and nitrogen may cause eutrophication of the receiving water bodies. Toxic compounds such as chromium and un-ionized ammonia that are directly toxic to aquatic life are also present in tannery effluents. It therefore seems essential to eliminate these pollution loads in the water before disposal (Amanial, 2016; Muthukkauppan and Parthiban, 2018).Tannery wastewater has been treated with many techniques such as coagulation, flocculation, ozonation, reverse osmosis, ion exchange, flotation, electrochemical treatment, sedimentation, filtration, ultra-filtration and adsorption (Bishnu et Al, 2016, Shegani, 2014).Flocculation appears more and more as not only a clarification process but also as a specific elimination treatment capable of minimizing the amount of these pollutants (Chowdhury et al. 2013, 2015; Amanial, 2016; Muthukkauppan and Parthiban, 2018). The generally used coagulants in tannery effluent treatment are: commercial aluminum sulphate $\left(\mathrm{Al}_{2}\left(\mathrm{SO}_{4}\right)_{3} \cdot 18 \mathrm{H}_{2} \mathrm{O}\right)$, commercial iron sulphate $\left(\mathrm{FeSO}_{4} \cdot 7 \mathrm{H}_{2} \mathrm{O}\right)$, commercial ferric chloride $\left(\mathrm{FeCl}_{3} \cdot 6 \mathrm{H}_{2} \mathrm{O}\right)$, and lime $(\mathrm{CaO})$ (Bishnu et Al., 2016) . Thus, treatment of tannery wastewater is always required. It is an obligatory process that sanitizes leather effluents in order to avoid degradation of the receiving terrestrial and aquatic systems in the vicinity of the discharge points (Mwinyihija , 2012). More specifically, the goal is to rid the wastewater of pollutants such as organic matter, chloride, sulfate, sulfide, nutrients, chromium, suspended solids, and other dissolved solids.

Objectives of coagulation typically include lower water consumption, improved uptake of chemicals, better quality/reusability of solid waste, and reduced content of specific pollutants such as heavy metals and electrolytes (UNIDO, 2011).

During this study, waste water generated during soaking and liming stages and during the tanning stage (deliming and vegetable tanning) was sampled and the different physico-chemical properties determined. These waste water samples were then treated by flocculation method and the efficiency of the process evaluated by comparing the physico-chemical properties of raw and treated waste water with results contained in the tannery's environmental impact study reports and standards (pollution thresholds)(WHO, 2004, 2017).

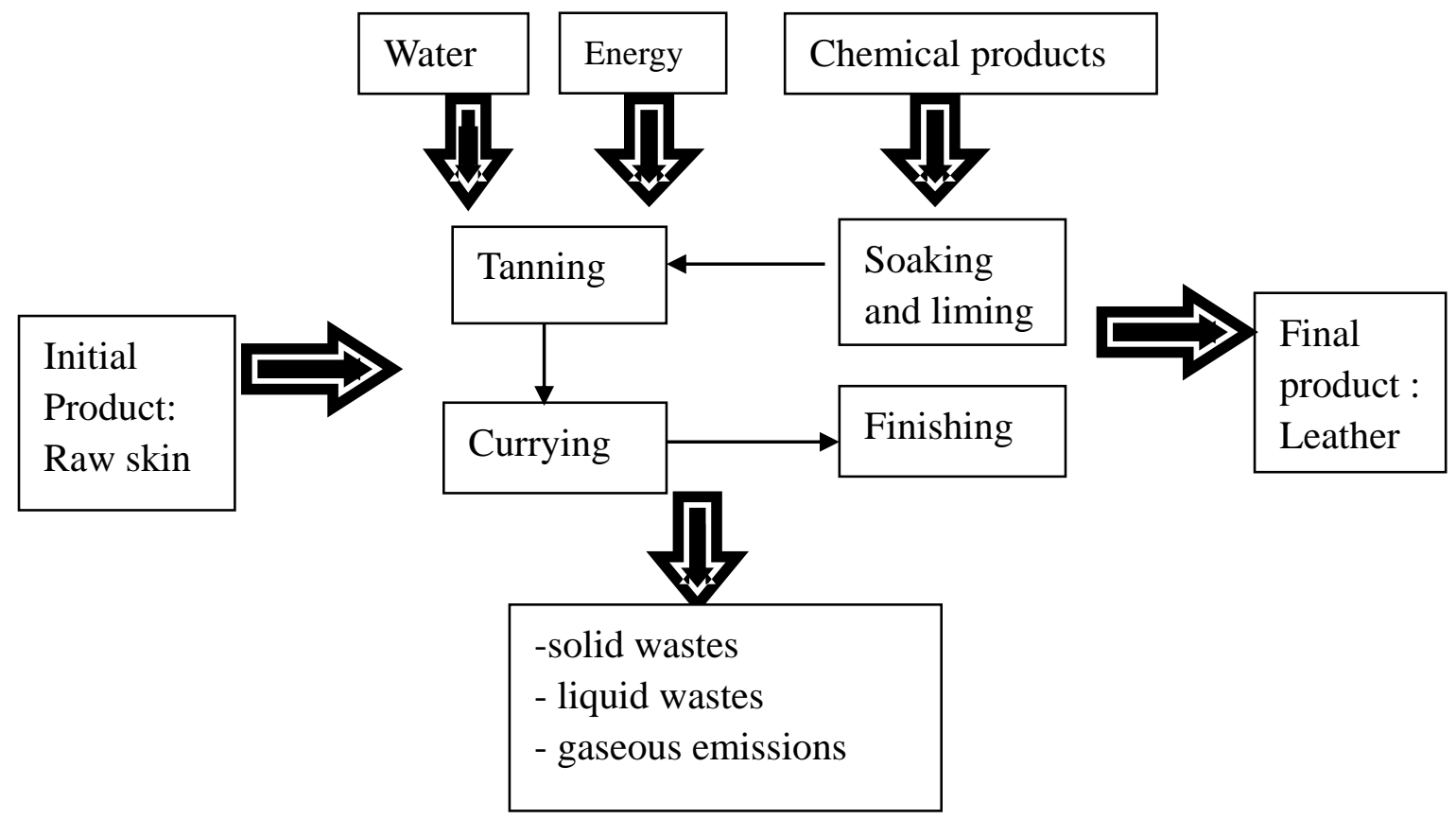

Figure 1. General scheme for leather manufacturing process

\section{Materials and Methods}

\subsection{Presentation of the Study Area}

The tannery industry of Maroua is still very traditional. It is located in the pontvert neighbourhood around the Ferngo (Madjema) forest zone along the Maroua-Mindif highway as shown in figure 2. As a water-consuming industry, our study area has a borehole and a well as its source of water supply. The effluents concerned in this study were sampled in the soaking (N $10^{\circ} 36.972^{\prime} \mathrm{E} 014^{\circ} 19.386^{\prime}$, Alt $424 \mathrm{~m}$ ) and liming (N $10^{\circ} 35.625^{\prime} \mathrm{E} 014^{\circ} 20.455^{\prime}$; Alt $\left.423 \mathrm{~m}\right)$ stages and during the tanning stage (deliming (N $10^{\circ} 35.628^{\prime}$ E $014^{\circ} 20.445^{\prime}$; Alt $\left.391 \mathrm{~m}\right)$ and vegetable tanning (N $10^{\circ} 36.971^{\prime} \mathrm{E}$ 
014 19.379’; Alt $414 \mathrm{~m})$ ). The coordinates of the sampling points were determined using a GARMIN etrex 10 GPS. The collected waste water of these different processes had various colors as shown in figure 3 . While some parameters of the collected waste water were determined in situ (temperature, $\mathrm{pH}$, conductivity and total dissolved solids), others that need more detailed analytical procedures were done using samples of waste water stored in a refrigerator at about $4^{\circ} \mathrm{C}$. This tannery employs two tanning techniques; chrome tanning using salts of the chromium (III) (For example the sulphate of chromium (III)) and plant tanning using the fruits of acacia (Acacia niloticavarietytomentosa).

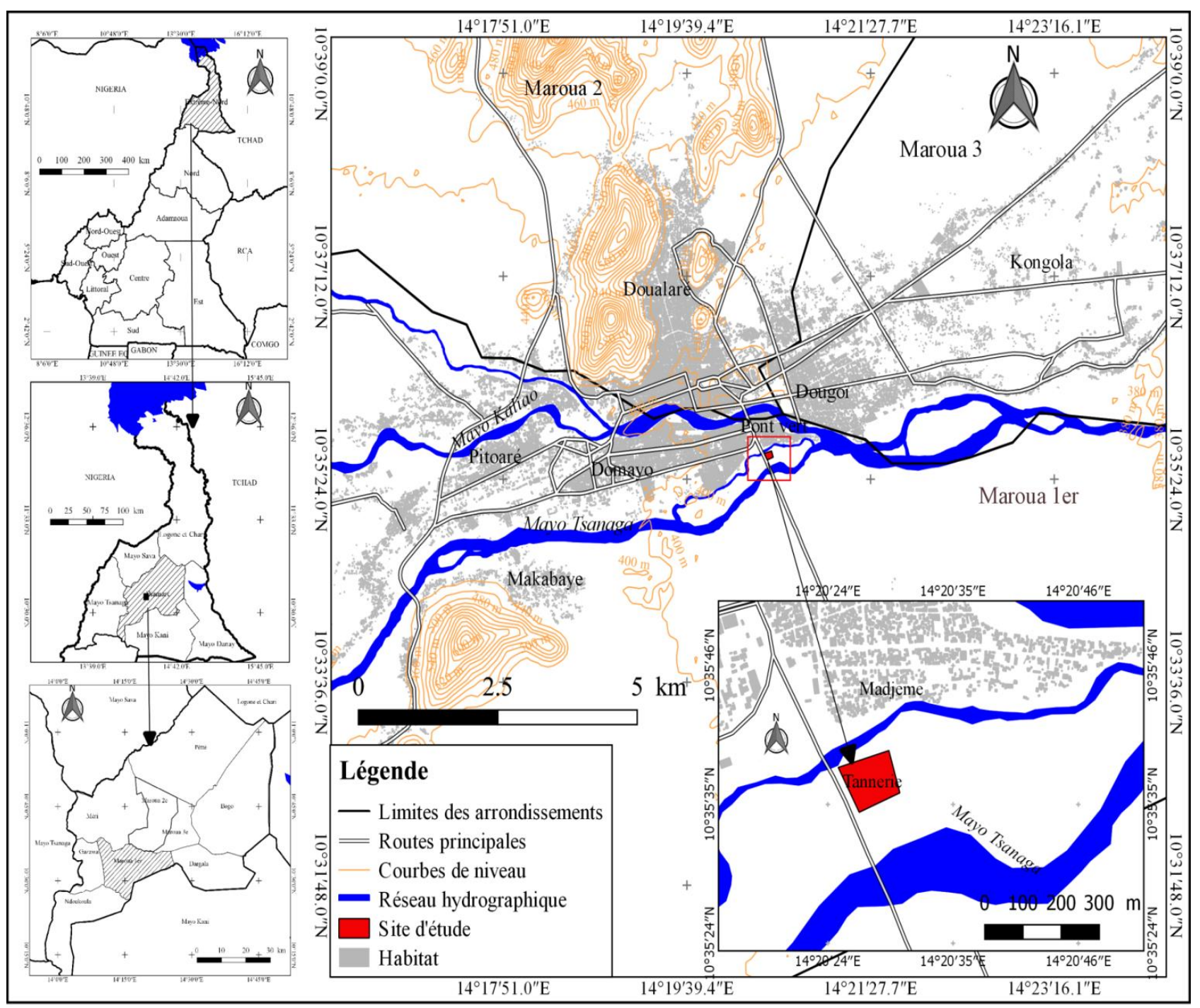

Figure 2. Map of study area 


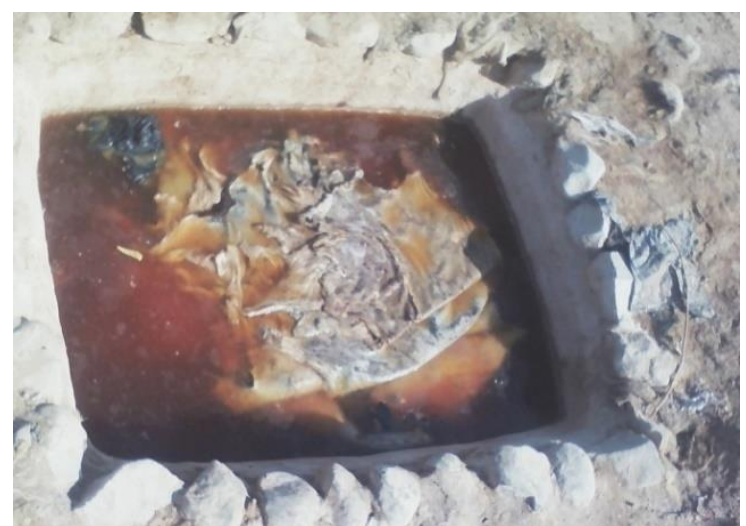

Photo 1. Soaking water

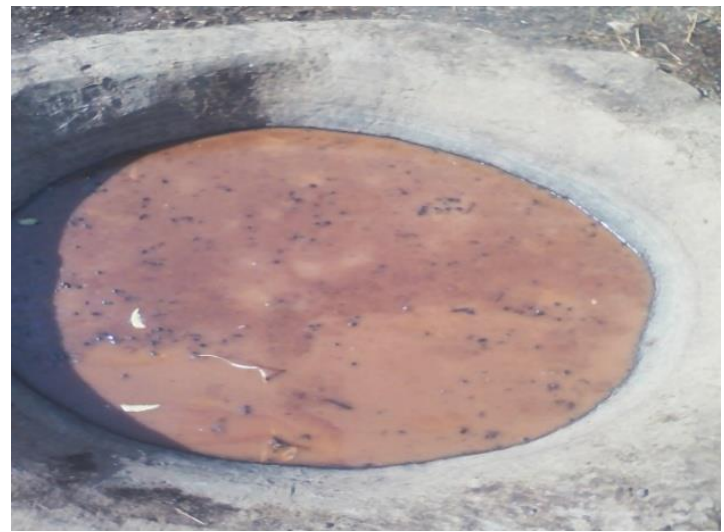

Photo 3. Water of deliming

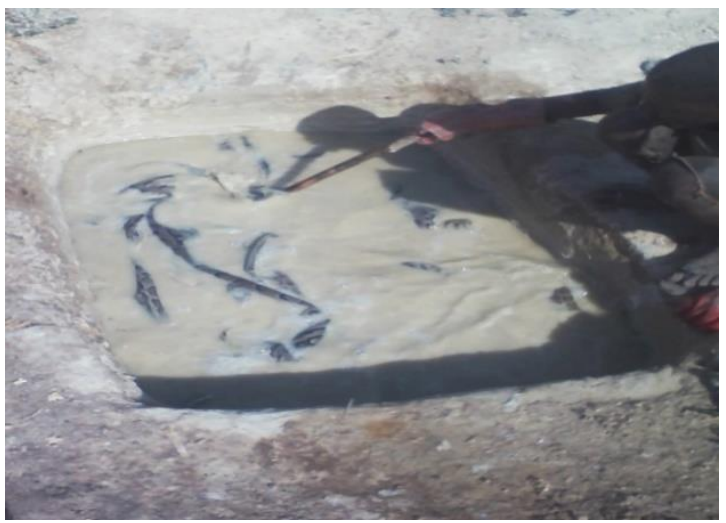

Photo 2. Liming water

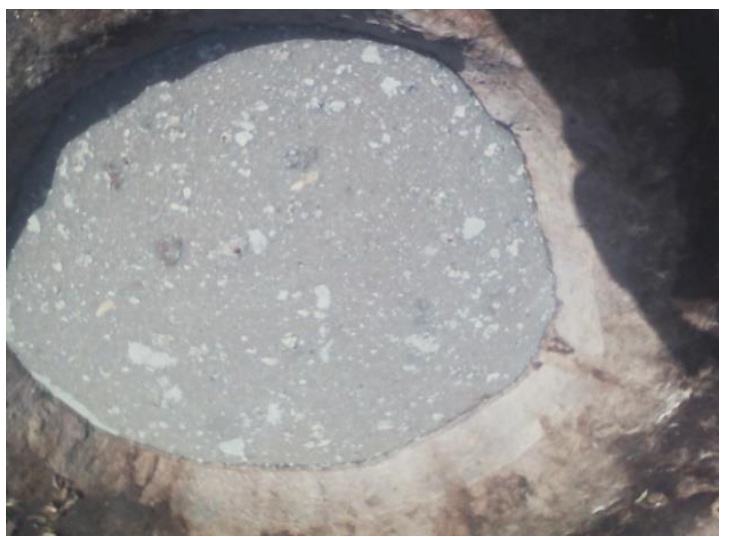

Photo 4. Vegetable tanning water

Figure 3. Overview of the coloration of the different waste water samples from different tanning operations

\subsection{Methods}

\subsubsection{Analytical Methods}

All analyses were performed on raw waste water collected from the four tanning stages shown in figure 3 as well as their treated samples.

The Physico-chemical parameters such as temperature, $\mathrm{pH}$ and conductivity $\left(\mu \mathrm{Scm}^{-1}\right)$ were measured in situ using an Extech pH-conductibility EC 500 multiparameter while Total suspended solids (TSS) was determined using APHA method and using EC-TDS Scan (APHA, 1995; Zaharin et al., 2007).

Total Hardness was determined by complexometric titration using Eriochrome Black-T as an indicator by EDTA method and Chloride was estimated by Mohr's method using $\mathrm{AgNO}_{3}$ solution and Potassium Chromate as an indicator (APHA, 1985; Abba et al., 2018)

The amount of dissolved oxygen was determined by acid-medium determination $\left(\mathrm{H}_{2} \mathrm{SO}_{4}\right)$ with a solution of sodium thiosulfate in the presence of manganese sulphate (APHA, 1998).

The chemical oxygen demand was determined by acid oxidation using an excess of potassium dichromate at the temperature of $148{ }^{\circ} \mathrm{C}$ of the oxidizable materials under the reaction conditions in the presence of silver sulphate as catalyst and sulphate of mercury (APHA, 1998; Abba et al., 2018).

The $\mathrm{BOD}_{5}$ was measured using a device that records the amount of oxygen supplied to restore the initial pressure of oxygen as needed: it is the respirometric system of Sierp.

The determination of nitrates was done according to the method recommended by Rodier, known as sodium salicylate method. In the presence of this reagent, the nitrates are transformed into nitrosalycitric acid characteristic of a yellow coloring in basic medium which was then analyzed using a UV-Visible spectrophotometer at $415 \mathrm{~nm}$ (Rodier, 2009).

The measurement of the ionic activity of ammonia under well-defined experimental conditions of ion concentration and $\mathrm{pH}$, makes it possible to determine the concentration of ammonium in water (Rodier, 2009).

The sulphide concentration was obtained by titration with iodine in the presence of starch (Rodier, 2009). Turbidity was measured using an EXTECH EC500 brand Multimeter. 


\subsubsection{Coagulation/Flocculation Treatment of Waste Water Samples}

Flocculation is one of the effective methods for removing these colloidal particles in water. It constitutes all physico-chemical phenomena leading to the aggregation of stabilized particles to form flakes or flocs. It allows the formation of aggregates by accelerating phase separation (Bishnu et Al., 2016).

In our tests, aluminum sulfate coagulant reagent was prepared by dissolving aluminum sulfate powder $\left(\mathrm{Al}_{2}(\mathrm{SO} 4)_{3}\right.$, $18 \mathrm{H}_{2} \mathrm{O}$ ) in distilled water. A $500 \mathrm{~mL}$ sample of the effluent was collected from each of the sampling points (soaking, liming, deliming and vegetable tanning stages) using a polyethylene bottle previously cleaned with dilute nitric and effluent of the sampling point concern. $500 \mathrm{mg}$ of coagulant reagent was mixed well with $500 \mathrm{~mL}$ of the effluent sample for 15 minutes. The mixture was then allowed to stand undisturbed for 24 hours in the dark at room temperature for proper settling and interaction with the coagulant. The supernatant liquids were separated from the deposited sludge by decantation and used for various physico-chemical analyses.

\section{Results and Discussion}

\subsection{Results Analysis}

The results of the analyses of the waters of the traditional tannery of Maroua, taken from four process stages that consumes water (soaking, liming, deliming, vegetable tanning) prior to treatment are presented in Table 1 while results obtained after Coagulation/Flocculation treatment are presented in Table 2. These results are compared to WHO standards which indicate the acceptable limit for domestic use of this water.

Table 1. Physico-chemical characteristics of the untreated tannery waste water

\begin{tabular}{l|l|l|l|l|l}
\hline Parameters & Soaking & Liming & Deliming & Tanning & $\begin{array}{l}\text { WHO standard } \\
(\mathbf{2 0 0 4 , 2 0 1 7})\end{array}$ \\
\hline Temperature $\left({ }^{\circ} \mathrm{c}\right)$ & 23 & 32 & 29 & 24 & 25 \\
\hline $\mathrm{pH}$ & 8,4 & 12,7 & 9,1 & 7,1 & $6,5-8,5$ \\
\hline Conductivity $(\mu \mathrm{S} / \mathrm{cm})$ & 4600 & 2300 & 5700 & 3500 & 400 \\
\hline Turbidity $(\mathrm{FTU})$ & 72 & 128 & 97 & 106 & 250 \\
\hline TSS $(\mathrm{mg} / \mathrm{L})$ & 1600 & 4700 & 3790 & 5300 & 250 \\
\hline $\mathrm{COD}\left(\mathrm{mg} \mathrm{O}_{2} / \mathrm{L}\right)$ & 10670 & 18330 & 8560 & 7630 & 44 \\
\hline $\mathrm{O}_{2}(\mathrm{mg} / \mathrm{L})$ & 1,9 & 0,9 & 1,2 & 0,8 & 50 \\
\hline BOD $_{5}\left(\mathrm{mg} \mathrm{O}_{2} / \mathrm{L}\right)$ & 4168 & 7100 & 3119 & 3042 & 50 \\
\hline Nitrate $(\mathrm{mg} / \mathrm{L})$ & 85 & 167 & 72 & 203 & 200 \\
\hline ammonium Ion $(\mathrm{mg} / \mathrm{L})$ & 314 & 510 & 240 & 860 & 30 \\
\hline Sulfide $(\mathrm{mg} / \mathrm{L})$ & 5,6 & 6,4 & 6,8 & 16,2 & 5 \\
\hline Hardness $(\mathrm{mg} / \mathrm{L})$ & 134 & 45 & 79 & 70 & 100 \\
\hline Chloride $(\mathrm{mg} / \mathrm{L})$ & 4756 & 125 & 86 & 741 & 250 \\
\hline
\end{tabular}


Table 2. Physico-chemical characteristics of the treated tannery waste water

\begin{tabular}{l|l|l|l|l|l}
\hline Parameters & Soaking & Liming & Deliming & Tanning & $\begin{array}{l}\text { WHO Standard } \\
(\mathbf{2 0 0 4 , 2 0 1 7})\end{array}$ \\
\hline Temperature $\left({ }^{\circ} \mathrm{c}\right)$ & 22 & 30 & 30 & 25 & 25 \\
\hline $\mathrm{pH}$ & 7,6 & 7,7 & 7,6 & 7,3 & $6,5-8,5$ \\
\hline Conductivity $(\mu \mathrm{S} / \mathrm{cm})$ & 14500 & 13500 & 15300 & 12400 & 400 \\
\hline Turbidity $(\mathrm{FTU})$ & 10 & 23 & 16 & 14 & 250 \\
\hline TSS $(\mathrm{mg} / \mathrm{L})$ & 20 & 30 & 30 & 20 & 250 \\
\hline $\mathrm{COD}\left(\mathrm{mg} \mathrm{O}_{2} / \mathrm{L}\right)$ & 5160 & 7450 & 3150 & 2840 & 44 \\
\hline $\mathrm{O}_{2}(\mathrm{mg} / \mathrm{L})$ & 5,6 & 4,3 & 5,5 & 5,2 & 50 \\
\hline BOD $\left(\mathrm{mg} \mathrm{O}_{2} / \mathrm{L}\right)$ & 2434 & 4146 & 1821 & 1776 & 50 \\
\hline Nitrate $(\mathrm{mg} / \mathrm{L})$ & 79 & 122 & 67 & 153 & 200 \\
\hline ammonium Ion $(\mathrm{mg} / \mathrm{L})$ & 184 & 491 & 232 & 838 & 30 \\
\hline Sulfide $(\mathrm{mg} / \mathrm{L})$ & 2,4 & 5,6 & 3,1 & 6,5 & 5 \\
\hline Hardness $(\mathrm{mg} / \mathrm{L})$ & 40 & 10 & 24 & 26 & 100 \\
\hline Chloride $(\mathrm{mg} / \mathrm{L})$ & 1236 & 77 & 45 & 324 & 250 \\
\hline 3.2 & & & & &
\end{tabular}

\subsection{Discussion of Results}

\subsubsection{Colour et Odour}

The odor was very strong in untreated effluents and significantly less potent after treatment. However, effluents regained their characteristic odor once the effluent samples were treated with heat (i.e. boiling) ( Shegani, 2014).The cloudy color and the nauseous odor of the waste water of the traditional Maroua tannery show a pollution of the receiving environment and thus not only having negative effects on the health of the workers but the environment as a whole. After the flocculation treatment, there was an effective decrease in the odour and colour of this water.

\section{$3.2 .2 \mathrm{pH}$}

The values obtained in the soaking and vegetable tanning steps are within the standard, but those obtained in the liming and deliming steps are higher than the WHO standard (6.5 - 8.5), Table 1 for untreated waste water samples. It appears therefore that these waters are alkaline. The $\mathrm{pH}$ values obtained are comparable to those found elsewhere for tannery wastewater with a basic pH (Ezzaouaq 1991, El Blidi et al., 2003, Himmi et al., 2003). From Table 2, it can be seen that Flocculation treatment improves the $\mathrm{pH}$ values to recommended standards (WHO, 2004, 1987, Semerjian and Ayoub, 2003; Imran et al;, 2012; Bishnu et Al., 2016).

\subsubsection{Conductivity}

Results of conductivity measurements for untreated samples ranged from 2300 to $5700 \mu \mathrm{S} / \mathrm{cm}$ (Table 1). These results show a strong mineralization in these waters and therefore a high concentration of dissolved salts. These high values of conductivity indicate a significant use of salts during the tanning process. These values remain well above the WHO standard value $400 \mu \mathrm{S} / \mathrm{cm}$ for surface water. It is observed from Table 2 that Flocculation considerably increases the activity of those ions present in tannery water as they had remained inactive due to the high concentration of organic matter(Ndabigengesere et al.,1998).

\subsubsection{Turbidity}

The average turbidity values recorded on the different samples of the traditional Maroua tannery (Table 1) are higher than the WHO standard. This is due to the presence of suspended matter: organic particles from decomposition and microorganisms. The physico-chemical treatment applied to these waters resulted in an average reduction of $73 \%$ in turbidity. The flocculation treatment thus reduced the repulsive charges and created chemical or electrostatic bonds between the suspended particles and facilitated the formation of the flocs, which were then decanted and then removed by filtration.

\subsubsection{Suspended Solids}

The concentrations of suspended solids recorded in the different samples varied between 1600 and $5300 \mathrm{mg} / \mathrm{L}$ (Table 1) which are well above the standard of $1000 \mathrm{mg} / \mathrm{L}$ (WHO, 2004). 
These high levels of suspended matter can be considered as a form of pollution (Rodier, 2009). Such an increase can lead to a warming of the water, which will have the effect of reducing the quality of the habitat for the cold water organisms (Hébert and Légare, 2000). The treatment of these waters by flocculation reduces the concentrations of suspended solids by approximately $96 \%$ (Table 2 ).

\subsubsection{Chemical Oxygen Demand (COD)}

COD is a measurement of the oxygen equivalent of the organic matter in a sample which is affected by oxidation of a

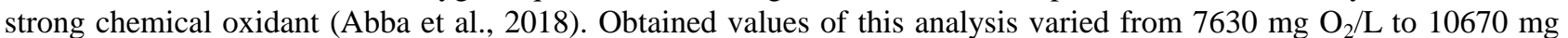
$\mathrm{O}_{2} / \mathrm{L}$, well above the maximum value of $250 \mathrm{mg} \mathrm{O}_{2} / \mathrm{L}$ expected by WHO, Table 1 . These high values of the chemical oxygen demand reflect the presence of a very large amount of organic matter and particularly presence of biologically resistant organics, hence the toxic nature of these effluents. Thus, the water of the traditional tannery of Maroua constitutes a source of pollution for the receiving environment (Desjardins, R. 1997). The flocculation treatment was able to reduce about 55\% on average of COD (Table 2), thus decreasing the toxicity of these waters.

\subsubsection{Biological Oxygen Demand $\left(\mathrm{BOD}_{5}\right)$}

$\mathrm{BOD}_{5}$ refers to quantity of oxygen needed by microorganisms for biological decomposition of dissolved solids or organic matter in effluents under aerobic conditions (Abba et al., 2018). Values ranging from 3042 to $7100 \mathrm{mg} \mathrm{O}_{2} / \mathrm{L}$ were obtained, indicating an organic pollution (WHO, 2004). The high content of $\mathrm{BOD}_{5}$ could be explained by the abundance of organic matter from skins and animal waste. The physicochemical treatment applied to this water decreases the organic load to about $54.5 \%$ and thus brings back water that is highly toxic to water that is moderately toxic to the environment.

\subsubsection{Dissolved Oxygen (DO)}

Dissolved oxygen refers to microscopic bubbles of gaseous oxygen that are mixed in water and available to aquatic organisms for respiration, a critical process for almost all organisms. In our study area, the evolution of dissolved oxygen varied from 0.8 to $1.9 \mathrm{mg} / \mathrm{L}$ of $\mathrm{O}_{2}$, Table 1 .The values obtained in the liming, deliming and vegetable tanning stages indicate that these waters are highly polluted and close to anaerobic. This can occur when the process of oxidizing mineral waste, organic matter and nutrients consumes more oxygen than is available, hence, can increase the solubility of toxic elements and therefore pollution of nature. By subjecting these waters to flocculation treatment, there was an increase in the amount of dissolved oxygen (4 to $6 \mathrm{mg} / \mathrm{L}$ of $\mathrm{O}_{2}$, Table 2), characteristic of safe water.

\subsubsection{Chloride}

The chloride concentrations found in the waters of the traditional Maroua tannery (Table 1) ranged from 87 to 4875 $\mathrm{mg} / \mathrm{L}$. The highest value recorded in soaking comes from the cooking salt used for the preservation of the skin. The values obtained in the liming, deliming and tanning steps are all below the Moroccan standard set at $750 \mathrm{mg} / \mathrm{L}$ (Rejsek F, 2002) but higher than the WHO standard (Table 1). The flocculation treatment allows a partial reduction of this ion, but still above the norm (soaking and vegetable tanning), Table 2.

\subsubsection{Hardness}

It is observed from Table 1 that apart from soaking waste water sample, all other samples have total hardness values below WHO standard (Table 1). The high value for soaking is probably due to the initial origin of the water used and the products used in the manufacture of leather. The small value recorded at the liming stage is due to the complexation of calcium ions by lime (FANUSA, 2013). The aluminum sulphate used for flocculation precipitates these calcium and magnesium ions in the form of calcium and magnesium sulphate. Hence, the almost complete elimination of hardness. The flocculation treatment reduces the hardness by about $83 \%$ on average.

\subsubsection{Sulfide}

The sulfide content of the untreated samples varied from 5.6 to $16.2 \mathrm{mg} / \mathrm{L}$ (Table 1). The smallest value being recorded in the vegetable tanning step. These values are all lower than the standards thus, no sulfate effect of these waster waters on the receiving environment (Rodier, 2009). Nevertheless, the flocculation treatment decreases by $51 \%$ on average the quantity of sulfate initially present in the various samples (Table 2).

\subsubsection{Nitrate}

The nitrate ion content recorded during the analysis of the different samples ranged from 72 to $203 \mathrm{mg} / \mathrm{L}$ (Table 1). This large amount of nitrate ions can be explained by the use of livestock waste used in the deliming step and also the evolution of the ammoniacal nitrogen cycle. The results are higher than the predicted standard (WHO, 2004) of $44 \mathrm{mg} / \mathrm{L}$ and therefore pose a health risk to workers and the surrounding population (EPA, 2000). After the flocculation analysis, there is a slight variation of $8 \%$ in the amount of nitrate in these waters but still remains above the norms. 


\subsubsection{Ammonium Ion}

A concentration variation from 314 to $860 \mathrm{mg} / \mathrm{L}$ was obtained depending on the samples but all were above the limit value of the ammonium ion (WHO, 2004). This high concentration is as a result of the use of ammonium sulphate or animal waste during confection (Chapman et al., 1996). After the flocculation treatment, there was a slight decrease in the concentration of ammoniacal nitrogen in these waters $(8 \%)$. Flocculation by aluminum sulphate weakly reduces the ammonium ion in the water.

\section{Conclusions}

The physico-chemical characterization of waste water collected from soaking, liming, deliming and vegetable tanning stages of the traditional tannery of Maroua before and after Flocculation treatment was undertaken in this study. Results obtained where compared to WHO standards for domestic water quality to evaluate the potential risk of these waste water to the environment and human health. The traditional tannery of Maroua uses a large number of chemicals and produces huge amounts of wastewater and solid waste. During this study, we were able to highlight the toxicity of four effluents (soaking, liming, deliming and vegetable tanning), high consumers of water during the manufacture of leather. The results obtained during laboratory and field analyses of certain physico-chemical parameters such as: turbidity, conductivity, $\mathrm{pH}$, color, odor, TSS, COD, BOD5, $\mathrm{O}_{2}$, chloride, nitrate and ammonium ion are higher than those predicted by the international standard (WHO, 2004). These waters therefore constitute a pollution load for the receiving environment. The results obtained made it possible to classify these four effluents in order of toxicity as follows:

Liming water > vegetable tanning water > deliming water> soaking water. The treatment of these waste waters by flocculation using aluminum sulfides considerably reduces the concentrations of certain pollutant loads such as TSS, turbidity, hardness $(83 \%), \mathrm{COD}, \mathrm{BOD}_{5}$, sulfate, $(54 \%)$; but remains less effective on others such as nitrate, chloride and ammonium ion (8\%). There is also a decrease in $\mathrm{pH}$, an increase in dissolved oxygen and conductivity. The flocculation treatment thus considerably reduced the toxicity of these effluents, especially its organic load.

\section{References}

Abba, P., Tsamo, C., \& Abdoul, W. (2018). Study on Physico-Chemical Parameters of Wastewater Effluents from Cotton Development Plant of Maroua-Cameroon. J. Pure App. Chem. Res., 7(3), 230-238. https://doi.org/10.21776/ub.jpacr.2018.007.03.366

Amanial, H. R. (2016). Physico Chemical Characterization of Tannery Effluent and Its Impact on the Nearby River. Open Access Library Journal, 3, e2427. https://doi.org/10.4236/oalib.1102427

APHA, AWWA, WEF. (1998). In: Clesceri, L.S., Greenberg, A.E., Eaton, A.D. (Eds.), Standard Methods for the Examination of Water and Wastewater, 20th Edition. APHA, AWWA, WEF, Washington, DC, USA.

APHA. (1985). Standard Methods for examination of water and wastewater $18^{\text {th }}$ edn., APHA, AWWA, WPCF, Washington DC, USA.

APHA. (1995). Standard Methods for the Examination of Water and Wastewater (19th Ed. ed.). Washington DC: Water Environment Federation.

Besra, L., Sengupta, D. K., Roy, S. K., \& Ay, P. (2002). Polymer adsorption: its correlation with flocculation and dewatering of kaolin suspension in the presence and absence of surfactants. International Journal of Mineral Processing, 66, 183-202. https://doi.org/10.1016/S0301-7516(02)00064-9

Bishnu, C. B., Md. Ariful, I. J., \& Md. Abul, H. (2016). Tannery Wastewater Treatment by Simple Coagulation-Filtration Process Using Low Cost Coagulants.International, Conference on Mechanical, Industrial and Energy Engineering Khulna, BANGLADESH. ICMIEE160374, 1-5

Chapman, D., \& Kimstach, V. (1996). Selection of water quality variables. Water quality assessments: a guide to the use of biota, sediments and water in environment monitoring, Chapman edition, $2^{\text {nd }}$ ed. E and FN Spon, London, 59-126. https://doi.org/10.4324/NOE0419216001.ch3

Chowdhury, M., Mostafa, M. G., Biswas, T. K., \& Saha, A. K. (2013). Treatment of leather industrial effluents by filtration and coagulation processes. Water Res Ind, 3, 11-22. https://doi.org/10.1016/j.wri.2013.05.002

Chowdhury, M., Mostafa, M. G., Biswas, T. K., Mandal, A., \& Saha, A. K. (2015). Characterization of the Effluents from Leather Processing Industries. Environ. Process, 2, 173-187. https://doi.org/10.1007/s40710-015-0065-7

Desjardins, C. (1999). Simulation et étude en laboratoire de la floculation (Actiflo) à l'aide d'une procédure modifiée de jar test (Mémoire de maîtrise, École Polytechnique de Montréal.

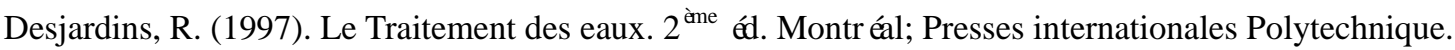


El Blidi, S., \& Fekhaoui, M. (2003). Hydrologie et dynamique marégraphique de l'estuaire du Sebou (Gharb, Maroc). Bull. Inst. Sci., 25, 57-65.

EPA: Environmental Protection Agency. (2000). Wastewater Technologie Fact Sheet, Chemical Precipitation, EPA 832-F-00-018, September 2000.

Ezzaouaq, M. (1991). Caractérisation hydrodynamique, physico-chimique et bactériologique des eaux superficielles de l'estuaire du Bouregreg (Maroc) soumis aux rejets des villes de Rabat-Salé. Thèse D.E.S. Fac. Sci. Rabat, 140p.

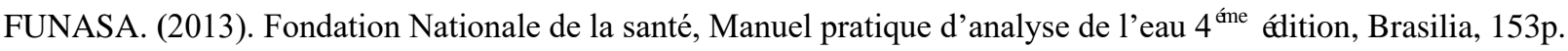

Hebert, S., \& Legre, S. (2000). Suivi de la qualité de l'eau des rivières et petits cours d'eau. Direction du suivi de l'état de l'environnement, Ministère de l'Environnement Gouvernement du Québec, 5 p.

Himmi, N., Fekhaoui, M., Foutlane, A., Bourchic, H., El Mmaroufy, M., Benazzout, T., \& Hasnaoui, M. (2003). Relazioneplankton-parametrifisicichimici in un bacinodimaturazione (lagunamista Beni Slimane - Morocco. Rivesta Di Idrobiologia. Universitadeglistudi di perugia, Departemento di Biologia Animale ed Ecologia laboratoire Di Idrobiologia "G.B. Grassi", 110-111p.

Imran, Q., Hanif, M. A., Riaz, M. S., Noureen, S. T. M., Ansari, T. M., \& Bhatti, H. N. (2012). Coagulation/Flocculation of Tannery Wastewater Using Immobilized Chemical Coagulants. Journal of Applied Research and Technology, 10, 79-86.

Muthukkauppan, M., \& Parthiban, P. (2018). A study on the physicochemical characteristics of tannery effluent collected from Chennai. International Research Journal of Engineering and Technology (IRJET), 5(3), 24-28.

Mwinyihija, M. (2012). Pollution control and remediation of the tanning effluent, The Open Environmental Pollution \& Toxicology Journal, 3, 55-64. https://doi.org/10.2174/1876397901203010055

Ndabigengesere, A., \& Narasiah. K. S. (1998). Quality of water treated by coagulation using Moringaoleifera seeds, Wat. Res., 32(3), 781-791. https://doi.org/10.1016/S0043-1354(97)00295-9

Rejsek, F. (2002). Analyse des eaux- Aspects réglementaires et techniques, Biologie technique CRDP d'aquitaine. 358p.

Rodier, J. et al. (2009). L'analyse de l'eau, $9^{\text {ème }}$ édition. DUNOD (éditeur), Paris, France.1579 p.

Semerjian, L., \& Ayoub. G. M. (2003). High-pH-magnesium coagulation-flocculation in wastewater treatment. Adv. Env. Res., 7, 389-403. https://doi.org/10.1016/S1093-0191(02)00009-6

Shegani, G. (2014). Treatment of Tannery Effluents by the Process of Coagulation.International. Journal of Environmental and Ecological Engineering, 8(4), 240-244.

UNIDO. (2011). Introduction to treatment of tannery effluents, Vienna, pp. 7-11, 18-21, 31-32.

W.H.O. (1987). Global pollution and health results of related environmental monitoring, Global Environment Monitoring system, WHO, UNEP.

W.H.O. (2004). Directives de qualité pour l'eau de boisson; Volume 2- critères d'hygiène et documentation a l'appui OMS, Genève, $2^{\text {ème }}$ Edition, $1050 \mathrm{p}$.

WHO, (2017). Guidelines for drinking-water quality: Fourth edition incorporating the first addendum. Geneva, Licence: CC BY-NC-SA 3.0 IGO

Zaharin, A. A., Harun, A. M., \& Kim, K. W. (2007). Hydrogeochemistry of Groundwater in Manukan Island, Sabah. The Malaysian Journal of Analytical Sciences, 11(2), 407-413.

\section{Copyrights}

Copyright for this article is retained by the author(s), with first publication rights granted to the journal.

This is an open-access article distributed under the terms and conditions of the Creative Commons Attribution license (http://creativecommons.org/licenses/by/4.0/). 